\title{
Precipitation Behaviour of Carbonitrides in Ti-Nb-C-N Microalloyed Steels and an Engineering Application with Homogenously Precipitated Nano-particles
}

\author{
Yanlin WANG ${ }^{1}$, Longchao ZHUO ${ }^{2,3}{ }^{*}$, Mingwen CHEN $^{4}$, Zidong WANG ${ }^{1}$ \\ ${ }^{1}$ School of Materials Science and Engineering, University of Science and Technology Beijing, Beijing 100083, China \\ ${ }^{2}$ School of Materials Science and Engineering, Xi'an University of Technology, Xi'an 710048, China \\ ${ }^{3}$ National Center for Electron Microscopy in Beijing, School of Materials Science and Engineering, Tsinghua University, \\ Beijing 100084, China \\ ${ }^{4}$ School of Mathematical and Physical Sciences, University of Science and Technology Beijing, Beijing 100083, China \\ crossref http://dx.doi.org/10.5755/j01.ms.21.4.9622
}

Received 27 January 2015; accepted 03 October 2015

\begin{abstract}
A thermodynamic model enabling calculation of equilibrium carbonitride composition and relative amounts as a function of steel composition and temperature has been developed previously based on the chemical equilibrium method. In the present work, actual carbonitride precipitation behaviour has been verified in the Ti-Nb-C-N microalloyed steels. The Ti microalloyed steel after refining with $0.012 \% \mathrm{Nb}$ exhibited highly improved tensile strength without sacrificing ductility. According to further detailed SEM and TEM analysis, the improved mechanical properties of Ti/Nb microalloyed steel could be attributed to the larger solubility of $\mathrm{Nb}$ and $\mathrm{Ti}$, inducing fine dispersion of the carbonitrides with particle size of $2-10 \mathrm{~nm}$ in the ferrite matrix.

Keywords: microalloyed steel, thermodynamic model, carbonitrides, precipitation.
\end{abstract}

\section{INTRODUCTION}

Microalloyed steels have been developed for many years and are widely used in industry today $[1,2]$. The microalloying elements, typically niobium, vanadium, and titanium, either individually or in combination, can significantly improve the strength and toughness of high strength low alloy (HSLA) steels through retarding recrystallization and grain growth of matrix at high temperatures and through dispersion hardening both in the matrix [3]. The matrix composition, the amount and composition of the carbonitrides, and heat treatment parameters are essential in determining the optimum composition for the HSLA steels. It is well acknowledged that the quantitative computation of balanced solid solubility of complex carbonitrides is one of the difficult problems in this area. Many experimental and theoretical studies on multicomponent carbonitride compositions based on minimization of Gibbs free energy have been carried out [4-6]. However, ideal stoichiometry of the carbonitride was usually assumed, and interstitial or metal vacancies were not considered. In addition, very little work has been done to examine and verify the limited models available. Recently, a thermodynamic model and computing method of solid solution precipitation of the carbonitrides have been developed according to mass balance and solubility product equations, and verified in Ti-V-C-N system by solving the equations through numerical methods [7]. On the other hand, despite the importance of combined precipitate and inclusion control in Ti-bearing microalloyed steels, little information is currently available in the literature on this issue [8]. To investigate this, thermodynamic assessment of carbonitride

\footnotetext{
* Corresponding author. Tel.:+86-29-82312191; fax: +86-29-82312191.

E-mail address: zhuolongchao@xaut.edu.cn (L. Zhuo)
}

precipitation behaviour in $\mathrm{Ti} / \mathrm{Nb}$ microalloyed steels has been evaluated and a concrete engineering application example is presented by the study of mechanical properties and microstructure analysis in this paper.

\section{EXPERIMENTAL}

The numerical iteration calculation process was carried out on Matlab 8.1 according to the model developed previously [7]. The sample steels were rapidly quenched to $650{ }^{\circ} \mathrm{C}$ after hot rolled at $1100{ }^{\circ} \mathrm{C}$ without subsequent heat treatment. Room temperature tensile tests were carried out on a CMT4105 testing machine according to GB/T2282002. Metallographic specimens were prepared using conventional grinding and polishing method. The phases of the alloy was investigated by $7000 \mathrm{~S}$ X-ray diffraction (XRD) with $\mathrm{Cu} \mathrm{K \alpha}$ radiation. The secondary electron images were obtained on a Carl-Zeiss Auriga scanning electron microscope (SEM) and the highly magnified imaging was carried out on FEI-Tecnai $\mathrm{G}^{2} 20$ transmission electron microscopy (TEM). The TEM samples were carefully grinded to produce a thin foil, followed by the electropolishing using a solution of $5 \%$ perchloric acid at $30{ }^{\circ} \mathrm{C}$.

\section{RESULTS AND DISCUSSION}

\subsection{Thermodynamic calculation for precipitation of carbonitrides in Ti-Nb-C-N steels}

Using numerical iteration method, for a series of $\mathrm{Ti} / \mathrm{Nb}$ microalloyed HSLA steels of $(0.05 \%-0.20 \%) \mathrm{C}$, $(0.003 \%-0.015 \%) \mathrm{N}, \quad(0.005 \%-0.035 \%) \mathrm{Nb}$ and $(0.005 \%-0.045 \%) \mathrm{Ti}$, the equilibrium thermodynamic state including the concentrations of the respective elements in solution $[\mathrm{C}],[\mathrm{N}],[\mathrm{Nb}]$ and [Ti] from $800{ }^{\circ} \mathrm{C}$ to 
full dissolution temperature, constants $k_{1}, k_{2}, m_{1}$ and $m_{2}$, as well as the total molar fraction of the carbonitrides has been investigated. According to the thermodynamic model [7] and the solubility products [9], the calculated full dissolution temperatures for different microalloyed HSLA steels are shown in Table 1. The carbonitride full dissolution temperature increases with increasing level of either $\mathrm{C}, \mathrm{N}, \mathrm{Nb}$ or $\mathrm{Ti}$ for various microalloyed steels. It should also be noted that the effect of $\mathrm{N}$ and Ti additions on the full dissolution temperature is expected to be greater compared with $\mathrm{C}$ and $\mathrm{Nb}$. As is known for HSLA steels, if the full dissolution temperature is above the liquidus temperature, carbonitrides constitutional liquation would occur, which is helpful to optimize steel composition.

Table 1. Full dissolution temperature of microalloyed HSLA steels with the composition variation of $\mathrm{C}, \mathrm{N}, \mathrm{Nb}$ and $\mathrm{Ti}$ in Ti-Nb-C-N systems

\begin{tabular}{|c|c|c|c|}
\hline \multicolumn{2}{|c|}{ Variation of C } & \multicolumn{2}{c|}{ Variation of N } \\
$-(0.006 \mathrm{~N}-0.015 \mathrm{Nb}-0.012 \mathrm{Ti})$ & \multicolumn{2}{|c|}{$-(0.1 \mathrm{C}-0.015 \mathrm{Nb}-0.012 \mathrm{Ti})$} \\
\hline $\mathrm{C}, \mathrm{wt} . \%$ & $\mathrm{~T}_{\mathrm{FD}},{ }^{\circ} \mathrm{C}$ & $\mathrm{N}, \mathrm{wt} . \%$ & $\mathrm{~T}_{\mathrm{FD}},{ }^{\circ} \mathrm{C}$ \\
\hline $0.05 \mathrm{C}$ & 1524.68 & $0.003 \mathrm{~N}$ & 1419.52 \\
\hline $0.10 \mathrm{C}$ & 1528.30 & $0.010 \mathrm{~N}$ & 1619.98 \\
\hline $0.20 \mathrm{C}$ & 1535.40 & $0.015 \mathrm{~N}$ & 1700.55 \\
\hline \multicolumn{2}{|c|}{ Variation of Nb} & \multicolumn{2}{|c|}{ Variation of Ti } \\
$-(0.1 \mathrm{C}-0.006 \mathrm{~N}-0.012 \mathrm{Ti})$ & $-(0.25 \mathrm{C}-0.006 \mathrm{~N}-0.015 \mathrm{Nb})$ \\
\hline $\mathrm{Nb}, \mathrm{wt} . \%$ & $\mathrm{~T}_{\mathrm{FD}},{ }^{\circ} \mathrm{C}$ & $\mathrm{Ti}, \mathrm{wt} . \%$ & $\mathrm{~T}_{\mathrm{FD}}{ }^{\circ} \mathrm{C}$ \\
\hline $0.005 \mathrm{Nb}$ & 1524.53 & $0.005 \mathrm{Ti}$ & 1392.26 \\
\hline $0.025 \mathrm{Nb}$ & 1532.01 & $0.025 \mathrm{Ti}$ & 1664.58 \\
\hline $0.035 \mathrm{Nb}$ & 1535.67 & $0.045 \mathrm{Ti}$ & 1790.99 \\
\hline
\end{tabular}



a

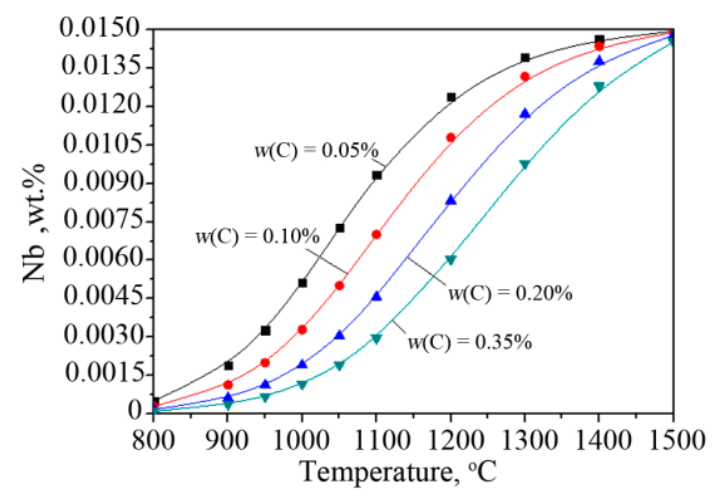

b

Fig. 1. Change of solid-soluted contents of $\mathrm{Ti}$ (a) and $\mathrm{Nb}$ (b) with $\mathrm{T}$ obtained from thermodynamic analysis of steels $0.012 \%$ Ti- $0.015 \% \mathrm{Nb}-0.006 \% \mathrm{~N}-(0.05 \%-0.35 \%) \mathrm{C}$

The calculation results of thermodynamic analysis of the Ti-Nb-C-N steels listed above are shown in Fig. 1-Fig. 4. At somewhat given temperature, the dissolved Ti content [Ti] decreases obviously with the increase of microalloying elements $\mathrm{N}$, while seems only slight change with the variation of microalloying $\mathrm{C}$ and $\mathrm{Nb}$ content.
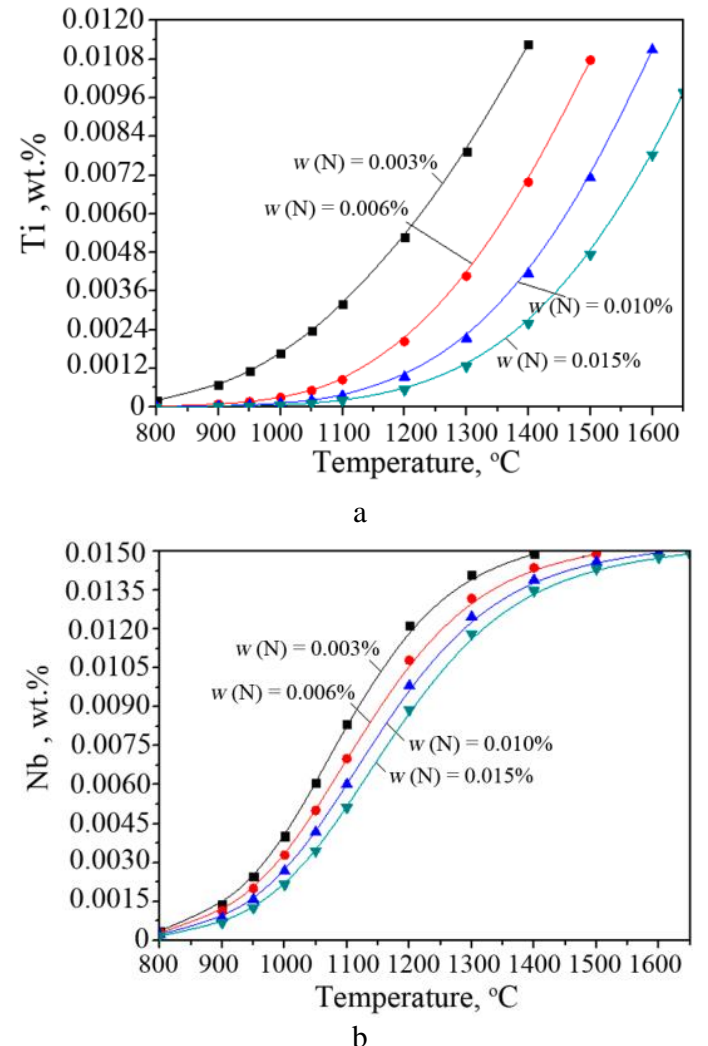

Fig. 2. Change of solid-soluted contents of $\mathrm{Ti}$ (a) and $\mathrm{Nb}$ (b) with $\mathrm{T}$ obtained from thermodynamic analysis of steels $0.012 \%$ Ti- $-0.015 \% \mathrm{Nb}-0.10 \% \mathrm{C}-(0.003 \%-0.015 \%) \mathrm{N}$

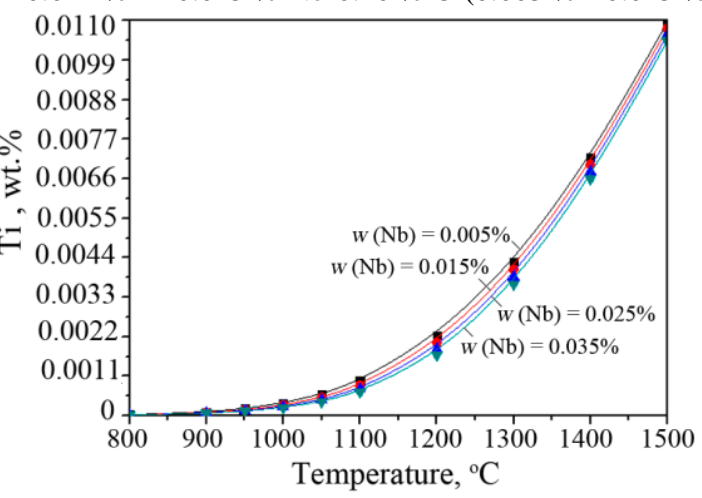

a

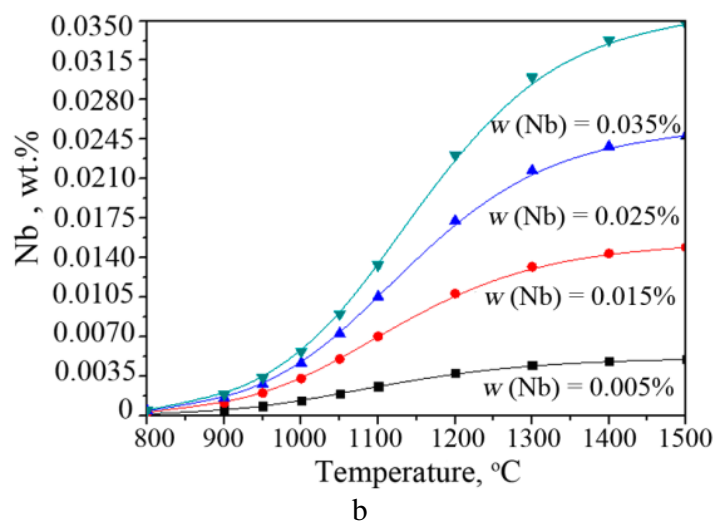

Fig. 3. Change of solid-soluted contents of $\mathrm{Ti}$ (a) and $\mathrm{Nb}$ (b) with $\mathrm{T}$ obtained from thermodynamic analysis of steels $0.012 \%$ Ti- $0.10 \%$ C- $0.006 \% \mathrm{~N}-(0.005 \%-0.035 \%) \mathrm{Nb}$ 
In contrast, the dissolved $\mathrm{Nb}$ content $[\mathrm{Nb}]$ increases reasonably with the content of microalloying $\mathrm{Nb}$, while decreases obviously with the increase of microalloying elements $\mathrm{C}, \mathrm{N}$ and $\mathrm{Ti}$. Therefore in engineering application, for higher [Nb] and [Ti] dissolved in steels, it is available to decrease the addition of $\mathrm{C}$ and $\mathrm{N}$ during alloy composition design.

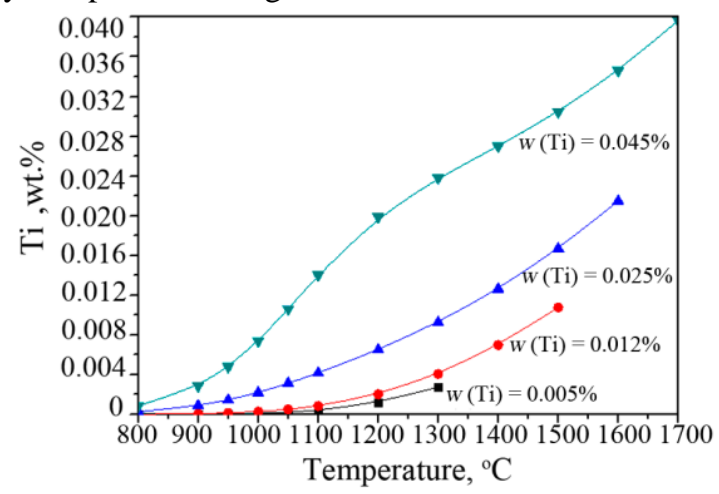

a

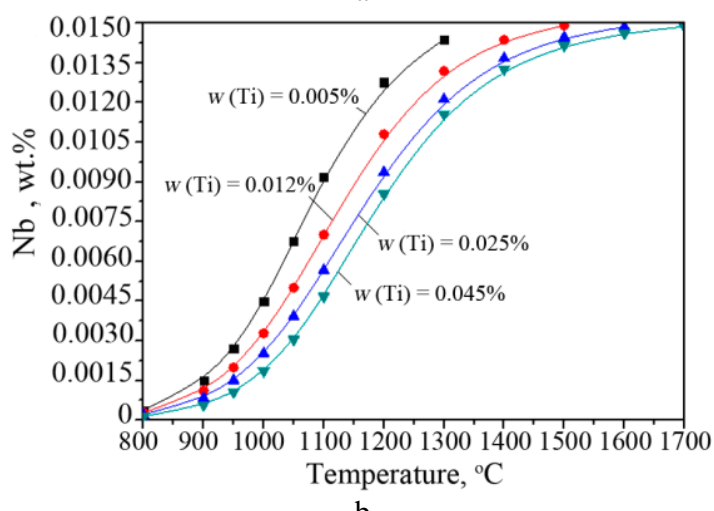

$\mathrm{b}$

Fig. 4. Change of solid-soluted contents of $\mathrm{Ti}$ (a) and $\mathrm{Nb}$ (b) with $\mathrm{T}$ obtained from thermodynamic analysis of steels $0.015 \% \mathrm{Nb}-0.10 \% \mathrm{C}-0.006 \% \mathrm{~N}-(0.005 \%-0.045 \%) \mathrm{Ti}$

Specifically, an engineering application of $\mathrm{Ti} / \mathrm{Nb}$ bearing steel was taken as an example here. The investigated samples have the similar composition except for free or bearing of microalloying element $\mathrm{Nb}$, as shown in Table 2.

Table 2. Nominal composition (wt.\%) of low carbon steels investigated

\begin{tabular}{|c|c|c|c|c|c|c|c|}
\hline & $\mathrm{C}$ & $\mathrm{N}$ & $\mathrm{Nb}$ & $\mathrm{Ti}$ & $\mathrm{Si}$ & $\mathrm{P}$ & $\mathrm{S}$ \\
\hline $\mathrm{S} 1$ & $\leq 0.23$ & $\leq 0.003$ & 0 & 0.004 & 0.25 & $\leq 0.025$ & $\leq 0.02$ \\
\hline $\mathrm{S} 2$ & $\leq 0.23$ & $\leq 0.003$ & 0.012 & 0.004 & 0.25 & $\leq 0.025$ & $\leq 0.02$ \\
\hline
\end{tabular}

For $\mathrm{Ti} / \mathrm{Nb}$ bearing microalloyed steel $\mathrm{S} 2$, the change of solid-soluted contents of microalloying elements and relative contents of binary precipitates with temperature can be obtained as shown in Fig. 5. As verified by the thermodynamic model, the dissolved [Nb] depends most remarkably on the variation of temperature (Fig. 5 a). The chemical composition of the carbonitrides expressed by the effective activity coefficients of $\mathrm{k}_{1}, \mathrm{k}_{2}, \mathrm{~m}_{1}$ and $\mathrm{m}_{2}$, strongly depends on the temperature (Fig. 5 b). The total molar quantity of the precipitated carbonitrides ( $t$ in Fig. $5 \mathrm{c}$ ) in $\mathrm{S} 2$ at $800{ }^{\circ} \mathrm{C}$ is only $2.1004 \mathrm{E}-4 \mathrm{~mol}$, indicating its minor tendency for precipitation. The real quantities of components $\mathrm{NbC}, \mathrm{TiC}, \mathrm{NbN}$ and $\mathrm{TiN}$ with the change of temperature can be approximated as shown in Fig. $5 \mathrm{~d}$. It should be noted that the precipitation of $\mathrm{NbC}$ and $\mathrm{TiN}$ dominates the whole composition of carbonitrides.

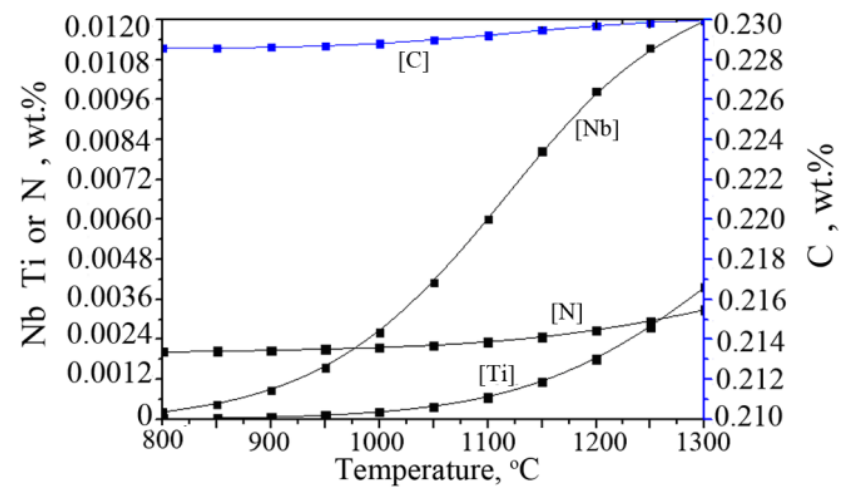

a

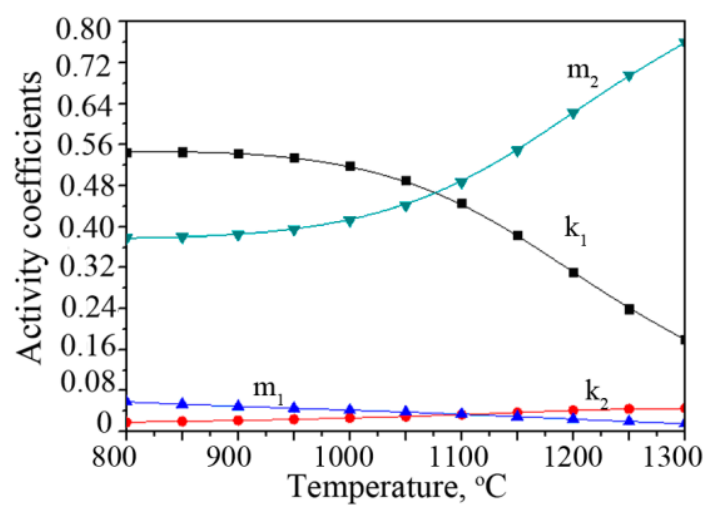

b

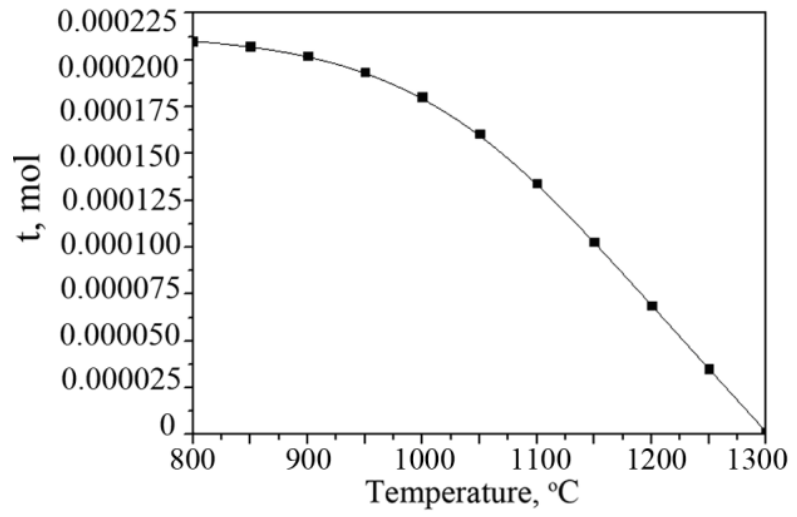

c



Fig. 5. Change of solid-soluted contents (a), component effective activity coefficients (b), total molar fraction of carbonitrides (c), and constants multiple total molar fraction of carbonitrides (d) with temperature $\mathrm{T}$ from analysis of steel S2 
In addition, the full dissolution temperature is calculated to be $1301.69{ }^{\circ} \mathrm{C}$ by the model, $212.61{ }^{\circ} \mathrm{C}$ lower than corresponding liquidus temperature of $1514.30^{\circ} \mathrm{C}$, which implies that no carbonitrides constitutional liquation would occur in the Nb-bearing steels; therefore, improved mechanical properties could be anticipated.

\subsection{Mechanical properties and microstructure investigation}

The yield strength $\sigma_{\mathrm{y}}$, tensile strength $\sigma_{\mathrm{t}}$ and specific elongation $\delta$ for steels $\mathrm{S} 1$ and $\mathrm{S} 2$ are shown in Table 3 .

Table 3. Mechanical properties measured respectively from steels $\mathrm{S} 1$ and $\mathrm{S} 2$

\begin{tabular}{|c|c|c|c|}
\hline Samples & $\sigma_{\mathrm{y}}, \mathrm{MPa}$ & $\sigma_{\mathrm{t}}, \mathrm{MPa}$ & $\delta, \%$ \\
\hline $\mathrm{S} 1$ & 390 & 518 & 24.5 \\
\hline $\mathrm{S} 2$ & 498 & 625 & 22.8 \\
\hline
\end{tabular}

For Ti-Nb-C-N microalloyed steels, Ti is employed as matrix grain growth prohibitor and $\mathrm{Nb}$ for precipitation strengthening and microstructure refinement, while $\mathrm{N}$ is used to enhance the effect of $\mathrm{Nb}$ and $\mathrm{Ti}[10,11]$. The improved tensile strength of $\mathrm{Ti} / \mathrm{Nb}$ microalloyed $\mathrm{S} 2$ without sacrificing specific elongation could be attributed to the more substantial solubility of $\mathrm{Nb}$ and $\mathrm{Ti}$, inducing fine dispersion of the carbonitrides in the ferrite matrix, which effectively increases the work hardening rate by promoting the accumulation of geometrically necessary dislocations around the particles $[12,13]$. Due to the minor alloying effect and small size of precipitated carbonitrides as investigated above, this has been verified in further detailed SEM and TEM analysis as shown in Fig. 6 a and Fig. 6 b.

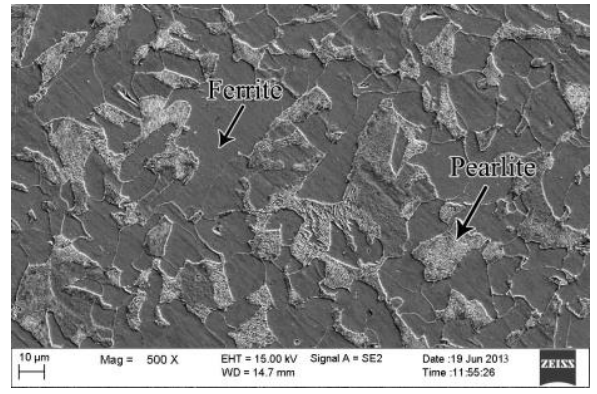

a

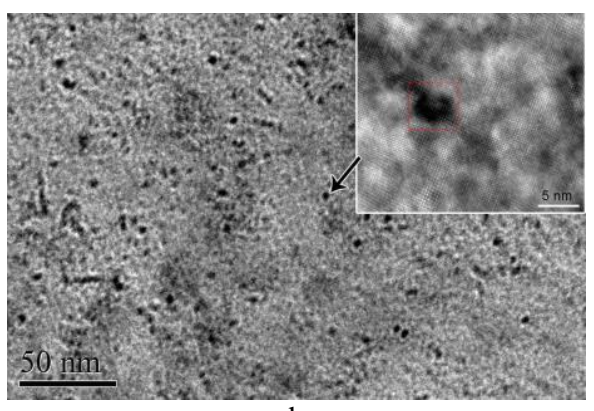

b

Fig. 6. Secondary electron SEM image (a) and bright field TEM image (b) of steel S2, the inset in (b) shows further magnified TEM image of a carbonitride particle

The homogenously distributed carbonitride particles precipitated in the ferrite matrix with the size range of $2-10 \mathrm{~nm}$ played a crucial role in the resultant properties. All existing phases have also been confirmed as shown in Fig. 7. Due to the minor alloying effect and small size of precipitated carbonitrides as investigated above, it is hard to detect their existence within the XRD resolution limit.



Fig. 7. XRD pattern of $\mathrm{Ti} / \mathrm{Nb}$ microalloyed steel $\mathrm{S} 2$

\section{CONCLUSIONS}

In this research, the equilibrium carbonitride composition and relative amounts as a function of steel composition and temperature have been calculated in Ti-Nb-C-N microalloyed steels. The results showed that:

1. The carbonitride full dissolution temperature increases with increasing level of either $\mathrm{C}, \mathrm{N}, \mathrm{Nb}$ or $\mathrm{Ti}$ for various microalloyed steels. The effect of $\mathrm{N}$ and $\mathrm{Ti}$ additions on the full dissolution temperature is expected to be greater compared with $\mathrm{C}$ and $\mathrm{Nb}$.

2. The $\mathrm{Ti}$ microalloyed steel after refining with $0.012 \% \mathrm{Nb}$ exhibited highly improved strength without sacrificing ductility. According to SEM and TEM analysis, the improved mechanical properties could be attributed to the more substantial solubility of $\mathrm{Nb}$ and $\mathrm{Ti}$, inducing fine dispersion of the carbonitrides with particle size of $2-10 \mathrm{~nm}$ in the ferrite matrix.

\section{Acknowledgement}

This work was financially supported by the Science and Technology Support Project of Jiangxi Province (grant no. 20112BBE50006), Young Scientists of Jiangxi Province Training Objects (grant no. 20133BCB23032) and the Scientific Research Foundation of Xi'an University of Technology (101-451115007).

\section{REFERENCES}

1. Deardo, A.J., Ratz, G.A., Wray, P.J. Thermomechanical Processing of Microalloyed Austenite. TMS-AIME Press, New York, 1982: pp. 33-58.

2. Gladman, T., The Physical Metallurgy of Microalloyed Steels. The Institute of Materials Press, London, 1997: pp. $185-200$.

3. Pardo, A., Merino, M.C., Coy, A.E. Influence of Ti, C and $\mathrm{N}$ Concentration on the Intergranular Corrosion Behaviour of AISI 316Ti and 321 Stainless Steels Acta Materials 55 (7) 2007: pp. 2239-2251.

4. Prikryl, M., Kroupa, A., Weatherly, G.C., Subramanian, S.V. Precipitation Behavior in a Medium Carbon, Ti-V-N Microalloyed Steel Metallurgical Materials Transactions A A27 (1) 1996: pp. 1149-1165. 
5. Hudd, R.C., Jones, A., Kale, M.N. A Method for Calculating the Solubility and Composition of Carbonitride Precipitates in Steel with Particular Reference to Niobium Carbonitride JISI 209 (1) 1971: pp. 121-125.

6. Yong, Q.L. The Second Phases in Steels. Metallurgical Industry Publishing, Beijing, 2006: pp. 202-203.

7. Wang, Y.L., Zhuo, L.C., Chen, M.W., Wang, Z.D. Thermodynamic Model for Precipitation of Carbonitrides in Microalloyed Steels and Its Application in Ti-V-C-N System Rare Metals 2015. http://dx.doi://10.1007/s12598-015-0495-4.

8. Vedani, M., Mannucci, A. Effects of Titanium Addition on Precipitate and Microstructural Control in C-Mn Microalloyed Steels ISIJ International 42 (12) 2012: pp. $1520-1526$.

9. Gan, Y. Practical Manual of Modern Continuous Casting Steel. Metallurgical Industry Press, Beijing, 2010: pp. $52-53$.
10. Hong, S.G., Jun, H.J., Kang, K.B., Park, C.G. Evolution of Precipitates in the Nb-Ti-V Microalloyed HSLA Steels during Reheating Scripta Materialia 48 (8) 2003: pp. $1201-1206$.

11. Song, R., Ponge, D., Raabe, D. Mechanical Properties of an Ultrafine Grained C-Mn Steel Processed by Warm Deformation and Annealing Acta Materialia 53 (18) 2005: pp. $4881-4892$.

12. Kimura, U., Inoue, T., Yin, F.X., Tsuzaki, K. Inverse Temperature Dependence of Toughness in an Ultrafine Grain-structure Steel Science $320(5879)$ 2008: pp. $1057-1060$.

13. Hu, J., Du, L.X., Wang, J.J. Effect of V on Intragranular Ferrite Nucleation of High Ti Bearing Steel Scripta Materialia 68 (12) 2013: pp. 953-956. 